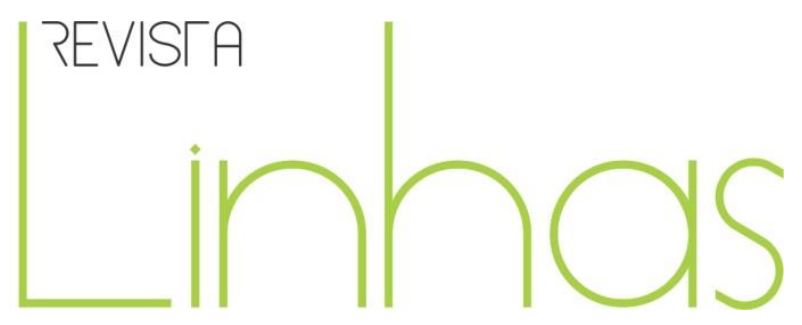

\title{
Planejamento coletivo por temas e avaliação descritiva em escola do campo - a experiência da Escola Básica Municipal José Maria ${ }^{1}$
}

\begin{abstract}
Resumo
Este artigo relata e analisa a experiência dos educadores da escola do campo - Escola Básica Municipal José Maria, sobre o planejamento coletivo por temas e avaliação diagnóstica, processual e descritiva, a fim de problematizar os conflitos e as limitações inerentes à construção e implantação das propostas, que ocorreu no espaço da formação continuada de educadores, entre os anos de 2012 a 2015. A escola está localizada em assentamento da reforma agrária, no município de Abelardo Luz - SC. Os pressupostos do método do Materialismo Histórico Dialético orientam a pesquisa. Nesse sentido, o texto apresentado contextualiza a escola do campo nos princípios de educação construídos pelo Movimento dos Trabalhadores Rurais Sem Terra (MST) e na concepção pedagógica da Educação do Campo; aponta a função da escola nesta concepção; apresenta a proposta de planejamento coletivo por temas e a iniciativa da escola em optar pela proposta de avaliação por parecer descritivo; relata o processo de implantação da avaliação descritiva, as dificuldades e o retorno ao processo de avaliação anterior. Conclui apontando as potencialidades, limites e desafios da experiência que demonstram a contradição do modelo escolar dentro do sistema capitalista hegemônico, a ponto de dificultar e até mesmo impedir, em parte, a efetivação de um projeto de transformação da escola, no caso, principalmente, à concretização da avaliação por parecer descritivo, que ainda no decorrer de um processo em construção, retrocede a nota.
\end{abstract}

Palavras-chave: Educação do Campo. Formação de Educadores. Movimento dos Trabalhadores Rurais Sem Terra.

\author{
Roseli Borowicc \\ Secretaria de Educação do \\ Estado de Santa Catarina - Brasil \\ rosebwc@gmail.com \\ Solange Aparecida Zotti \\ Instituto Federal Catarinense - \\ IFC - Campus Concórdia/SC - \\ Brasil \\ solange.zotti@ifc.edu.br
}

\begin{abstract}
Para citar este artigo:
BOROWICC, Roseli; ZOTTI, Solange Aparecida. Planejamento coletivo por temas e avaliação descritiva em escola do campo - a experiência da Escola Básica Municipal José Maria. Revista Linhas. Florianópolis, v. 19, n. 39, p. 55-79, jan./abr. 2018.
\end{abstract}

\section{DOI: $10.5965 / 1984723819392018055$}

http://dx.doi.org/10.5965/1984723819392018055

\footnotetext{
${ }^{1}$ Artigo produzido a partir do Trabalho de Curso da Especialização em Educação do Campo do Instituto Federal Catarinense - IFC, Campus Avançado de Abelardo Luz - SC.
} 


\title{
Collective planning by topics and descriptive evaluation in a country school - the experience José Maria the Municipal Basic School
}

\begin{abstract}
This article reports and analyzes the experience of the educators in a country school - José Maria the Municipal Basic School. It is about a collective planning by themes and diagnostic, procedural and descriptive evaluation. The purpose is to problematize the conflicts and limitations related to the construction and implementation of the proposals. These occurred in the space of continuing education of educators, from 2012 to 2015 years. The school is located in an agrarian reform settlement, in Abelardo Luz city - SC. The assumptions of the method is the Dialectic and Historical Materialism that guide this research. So, the text presented contextualizes the country school in the principles of education built by the Movement of Landless Rural area Workers (MST) and in pedagogical conception of Country Education; points out the purpose of the school in this conception; presents the proposal of collective planning by subjects and the initiative of the school in defining the proposal by descriptive evaluation; reports the process of implementation of descriptive evaluation, the difficulties and the return to the previous evaluation process. I concluded that this proposal pointing out the potential, limits and challenges of the experience that demonstrate the contradiction of the school model within the hegemonic capitalist system. Which difficult and even prevent, partially the implementation of a school transformation project, mainly related to the realization of the evaluation by a descriptive notes, that still in the course of a process under construction, goes back the performance.
\end{abstract}

Keywords: Country Education. Training of educators. Movement of Landles Rural Workers. 


\section{Introdução}

Este artigo objetiva relatar e analisar a experiência dos educadores da escola do campo - Escola Básica Municipal José Maria, sobre o planejamento coletivo por temas e avaliação diagnóstica, processual e descritiva, a fim de problematizar os conflitos e as limitações inerentes à construção e implantação das propostas, que ocorreu no espaço da formação continuada de educadores, entre os anos de 2012 a 2015.

A escola do campo, objeto da pesquisa, situa-se em área de assentamento da reforma agrária, no município de Abelardo Luz - SC, localizado no centro do Oeste de Santa Catarina, com 17.100 habitantes (IBGE, 2010), distribuídos de forma equilibrada entre o campo e a cidade. É um município essencialmente agrícola, que tem sua economia baseada na agropecuária, a partir de dois modelos de produção: de um lado, a produção de monocultivos (principalmente soja e milho) em grandes extensões de terras; de outro, assentamentos da reforma agrária e pequenas propriedades de agricultura familiar em comunidades rurais, com predomínio da produção de leite para comercialização e alimentos variados para a subsistência e renda.

O território era inicialmente composto por grandes propriedades de terras, muitas improdutivas, que não cumpriam seu papel social, conforme a Constituição da República Federativa do Brasil de 1988, art. 185, parágrafos I a IV: “aproveitamento racional e adequado; utilização adequada dos recursos naturais disponíveis e preservação do meio ambiente; observância das disposições que regulam as relações de trabalho; exploração que favoreça o bem-estar dos proprietários e dos trabalhadores” (BRASIL, 1988).

Por essa razão, o município foi fortemente marcado pela luta por reforma agrária, da qual resultaram, até o momento, 22 assentamentos e um acampamento, oriundos de diversas ocupações de terra organizadas pelo Movimento dos Trabalhadores Rurais Sem Terra (MST), desde o ano de 1985.

A Escola Básica Municipal José Maria foi conquistada junto à luta desses trabalhadores que, ao ocuparem um latifúndio improdutivo não estão apenas buscando a terra, mas condições dignas de vida que incluem moradia, saúde, educação, trabalho, condições para a produção de alimentos, entre outros direitos. O campo nesta perspectiva é considerado um lugar de vida e construção de cultura, em contraposição à 
lógica do capital que vê o campo somente como um lugar de negócio (FERNANDES, 2014, p. 97).

Nessa perspectiva, a educação do campo se coloca como alternativa à educação rural existente, que não supria as necessidades de conhecimento para a emancipação dos povos do campo (RIBEIRO, 2012). Os movimentos sociais do campo, a partir de meados da década de 1990, são os principais protagonistas junto aos órgãos governamentais pela luta por políticas educacionais voltadas para as necessidades específicas do campo (OLIVEIRA, 2013).

Como ponto de partida, esses movimentos sociais, em especial o MST, compreendem a educação como um direito de todos e um dever do estado. Afirmam, no bojo do movimento de luta por Educação do Campo, "a luta por políticas públicas que garantam aos trabalhadores do campo o direito a educação, especialmente a escola, e a uma educação que seja no e do campo" (CALDART, 2012, p. 259). No campo porque deve estar próxima e valorizar o lugar de vida dos sujeitos e do campo porque deve ser realizada de acordo com todos os princípios e elaborações pedagógicas da Proposta de Educação do Campo, construída pelos sujeitos do campo e suas organizações.

Esta pedagogia se contrapõe à "lógica do modelo dominante [...] de preparação de mão de obra para os processos de modernização e expansão das relações capitalistas na agricultura" (CALDART, 2012, p. 260), Por isso, se faz na contradição, na necessidade da luta permanente e contra hegemônica frente ao sistema capitalista, o que exige pensar a educação e a escola com base nos pressupostos teórico-metodológicos do Materialismo Histórico Dialético.

Nesse sentido, entendemos que o conhecimento das questões que envolvem e determinam a vida das pessoas no seu cotidiano, é capaz de, se colocado em ação, transformar a realidade. Portanto, trata-se do conhecimento da realidade e, ao mesmo tempo, das questões que interferem na realidade. Por isso, a importância do projeto de educação ser pensado a partir do contexto em que a escola está inserida e no interior da escola, com seus educadores, para que possam, conhecendo, serem agentes de transformação, tanto na formação dos estudantes, como nas intervenções na realidade em que vivem. 
Por isso, com base no exposto, a metodologia deste trabalho vincula-se à dialética marxista, por entender que a proposta de Educação do Campo nasce desta fonte, portanto entendemos que não é coerente pensar a Educação do Campo desvinculada desta concepção teórico-metodológica. A Educação é algo complexo e, quando busca formar os sujeitos em suas múltiplas dimensões - cognitiva, afetiva, física e social -, para compreender a realidade e transformá-la, a lógica formal, que separa sujeito-objeto não permite compreender a totalidade, sendo o método materialista histórico-dialético o caminho para esta possibilidade. Pires (1997, p. 86) traz a compreensão do método em Marx:

o método materialista histórico dialético, é método de interpretação da realidade, visão de mundo e práxis [...] Marx deu o caráter material (os homens se organizam na sociedade para a produção e a reprodução da vida) e o caráter histórico (como eles vêm se organizando através de sua história).

Com base no exposto, temos a consciência de que compreender o método é fundamental para a efetivação da pesquisa por seus meios, pois, para Pires (1997, p. 87), "é instrumentalizar-se para o conhecimento da realidade, no caso, a realidade educacional”. Nesta lógica, percebemos um caminho que leva em conta as contradições da realidade e que para compreendê-lo, se faz necessária uma inter-relação entre sujeito e objeto, de forma dialética, no caso da pesquisa, partindo da realidade empírica, colhida através de observações e da própria atuação no cotidiano da escola; da consulta e análise de documentos (registros feitos para o arquivo da escola e o Projeto Político Pedagógico - PPP), em que se procurou identificar os princípios norteadores da educação na escola pesquisada; e por meio do pensamento, das reflexões, da relação com as teorias já existentes, a fim de chegar a uma compreensão mais elaborada da realidade escolar, "o concreto pensado".

A coleta de dados empíricos foi realizada a partir dos registros feitos entre os anos letivos de 2012 e 2015. Neste período ocorreu a participação efetiva da pesquisadora ${ }^{2}$, juntamente com os demais educadores da escola, em todos os momentos de formação, no planejamento coletivo da escola, na discussão da proposta de avaliação descritiva, na

\footnotetext{
${ }^{2}$ Primeira autora do artigo.
} 
construção do instrumento da avaliação (boletim descritivo), na observação dos pareceres descritivos elaborados pelos educadores e na participação em reuniões de pais. Compreendem-se como interlocutores do processo toda a comunidade escolar: estudantes, pais, educadores e gestores, por entender como dados da pesquisa, todo o processo realizado, a interlocução com os educadores nas formações e planejamentos coletivos, as reuniões com os pais e as observações das reações dos mesmos quando buscavam o boletim dos filhos na escola.

O artigo está organizado em quatro seções e Considerações Finais, contando como primeira seção esta Introdução. Na segunda, apresenta os princípios do Projeto de Educação do MST e suas implicações na organização da escola em seus espaços de conquista; aborda a Educação do Campo, "fenômeno da realidade brasileira atual" (CALDART, 2012, p. 257), como uma nova forma de pensar a escola do campo. Na terceira seção apresenta o percurso da experiência realizada na escola no contexto da formação de educadores sobre o planejamento coletivo por temas e a avaliação por parecer descritivo; a quarta seção aborda a avaliação e a opção da escola por uma avaliação diagnóstica, processual e descritiva; as contradições e limites encontrados. As considerações finais sintetizam o potencial, os limites e as contradições da proposta construída pela Escola Básica Municipal José Maria e apontam a necessidade de ampliação da pesquisa no sentido do entendimento e transformação da forma escolar.

\section{Os princípios orientadores da educação no MST e a proposta de educação do campo}

O Movimento dos Trabalhadores Rurais Sem Terra (MST), em mais de trinta anos de história, vem construindo, com seus sujeitos, uma proposta de educação com princípios de luta pela libertação dos povos do campo. Da mesma forma, a proposta de Educação do Campo nasce a partir da luta, principalmente deste movimento, mas também de outros movimentos sociais do campo que, para além do direito à terra, trabalho e vida digna, lutam por educação. Fazem isso por acreditar que não há como construir uma nova sociedade sem que seus sujeitos tenham o conhecimento necessário para compreender e intervir na transformação da realidade. Por isso, consideram "a educação uma das dimensões da formação, entendida tanto no sentido amplo da 
formação humana, como no sentido mais restrito de formação de quadros para a nossa organização e para o conjunto das lutas dos trabalhadores" (MST, 2005, p. 161).

Cabe destacar que desde a origem do movimento de luta pela terra no sul do Brasil, no ano de 1979, em meio a grandes limitações, a construção de uma proposta de educação “diferente”, era pautada de forma coletiva, pelos pais, lideranças e educadores, nos primeiros acampamentos e assentamentos (MST, 2005, p. 11). Desta preocupação, a partir de estudos e debates coletivos, foram forjados os princípios da educação no MST, que passam a orientar os sujeitos que fazem este movimento, a fim de implementá-los nas escolas conquistadas. Estes princípios estão sistematizados no Caderno de Educação nº 8, Princípios da Educação no MST, publicado pela primeira vez em 1996.

Neste documento, o MST especifica os princípios filosóficos e pedagógicos que orientam a sua proposta de educação. Os princípios filosóficos dizem respeito à visão de mundo, às concepções mais gerais em relação à pessoa humana, à sociedade e ao que o movimento entende que seja educação, o que remete aos objetivos mais estratégicos do trabalho educativo no MST (MST, 2005). Em síntese, os princípios filosóficos são: $1^{\circ}$ ) Educação para a transformação social; $2^{\circ}$ ) Educação para o trabalho e a cooperação; $3^{\circ}$ ) Educação voltada para as várias dimensões da pessoa humana; $4^{\circ}$ ) Educação com/para valores humanistas e socialistas; $5^{\circ}$ ) Educação como um processo permanente de formação e transformação humana (MST, 2005, p. 161-165).

Os princípios pedagógicos dizem respeito aos elementos essenciais e gerais da proposta de educação para concretizar os próprios princípios filosóficos, especialmente a reflexão metodológica dos processos educativos, nos diferentes espaços educacionais (MST, 2005): $1^{\circ}$ ) Relação entre teoria e prática; $2^{\circ}$ ) Combinação metodológica entre processos de ensino e de capacitação (conhecimento na prática); $3^{\circ}$ ) A realidade como base da produção do conhecimento; $4^{\circ}$ ) Conteúdos formativos socialmente úteis; $5^{\circ}$ ) Educação para o trabalho e pelo trabalho; $6^{\circ}$ ) Vínculo orgânico entre processos educativos e processos políticos; $7^{\circ}$ ) Vínculo orgânico entre processos educativos e processos econômicos; $8^{\circ}$ ) Vínculo orgânico entre educação e cultura; $9^{\circ}$ ) Gestão democrática; $10^{\circ}$ ) Auto-organização dos/das estudantes; $11^{\circ}$ ) Criação de coletivos pedagógicos e formação permanente dos educadores/ das educadoras; $12^{\circ}$ ) Atitude e habilidade de pesquisa; $13^{\circ}$ ) Combinação entre processos pedagógicos coletivos e 
individuais (MST, 2005, p. 165-176).

Assim, ao lutar por terra, o camponês traz em seu imaginário todas as demais conquistas que podem vir com ela. O campo que o sem-terra procura não é o mesmo campo do agronegócio, que quer a terra para explorá-la, para o negócio, para tirar lucro dela. O camponês vê na terra muito mais que um lugar para cultivar um produto para vender e ganhar dinheiro. A terra, para ele, vai além da produção da subsistência, é o lugar de produzir sua vida. Um lugar de vida demanda de outros espaços além da terra, um lugar para morar, que tenha saúde, educação, lazer, cultura, organização, projeção de futuro. A Escola, objeto desta pesquisa está vinculada à construção histórica de luta por educação, realizada, lado a lado, com a luta pela terra.

Tais princípios de educação devem nortear as práticas pedagógicas das escolas em áreas de Reforma Agrária que tenham vínculo com este movimento social. Por isso, é essencial perceber como os princípios do projeto de educação do MST auxiliam a escola a cumprir seus objetivos e metas, na formação de educadores, no planejamento coletivo e em suas práticas pedagógicas. Na escola pesquisada, o Projeto Político Pedagógico (PPP) foi pensado e elaborado com base nestes princípios, que orientam a educação do campo, conforme destacamos a seguir:

\section{Objetivo geral da escola:}

Garantir o direito a educação do/no campo com qualidade social nos diversos níveis de ensino e que compreenda o educando como sujeito com capacidades de ordem cognitiva, física, afetiva, social, produzindo relações interpessoais pautados na ética e estética tendo em vista uma formação integral do ser humano, crítico e autônomo. (ESCOLA BÁSICA MUNICIPAL JOSÉ MARIA, 2014, p. 10)

Também, os conteúdos ensinados na escola, as metodologias de ensino e as formas de avaliação da aprendizagem devem atender aos princípios pedagógicos do MST descritos anteriormente, a fim de que a proposta da escola seja cada vez mais coerente com as necessidades e expectativas da comunidade, com vistas à construção de uma educação que contribua para a transformação social. Poder compreender mais profundamente estas questões é de suma importância para a contribuição que se pretende dar ao processo de educação que vem se constituindo a partir dos sujeitos que 
o fazem nesta realidade. Para a Educação do Campo, a tarefa é de formar sujeitos capazes de produzir seu destino e transformar seus espaços de vida, pois como afirmam Kolling; Cerioli e Caldart (2002, p. 19):

Temos uma preocupação prioritária com a escolarização da população do campo. Mas, para nós, a educação compreende todos os processos sociais de formação das pessoas como sujeitos de seu próprio destino. Nesse sentido, a educação tem relação com a cultura, com valores, com jeito de produzir, com formação para o trabalho e para a participação social.

A Educação do Campo, desde sua origem, construída por seus sujeitos, é feita de luta no contexto das contradições da sociedade capitalista. Na atualidade, com a ascensão de forças de direita, reacionárias, a expansão do agronegócio e a instalação de empresas no meio rural, a educação do campo tem o desafio de defender sua identidade, porque ao ser normatizada como política pública de governo, corre o risco de ser desvirtuada de sua origem, questão que vem sendo discutida por autores como Cherobin (2015). O desafio é também de ampliar e aprimorar os conhecimentos, a partir de seu método original da "prática para a teoria e da teoria para a prática" (CALDART, 2012, p. 262), no sentido de ter sua forma pedagógica ampliada, entendida e praticada para poder realmente superar as adversidades e formar sujeitos "lutadores e construtores", como diz o lema do VI Congresso Nacional do MST (2014).

Neste sentido e, segundo Caldart (2014) 3 , “não se pode falar em Educação do Campo, que guarda as características de sua identidade, sem fazer o debate da forma de agricultura que defende". Utilizando o conceito de agrobiodiversidade, a autora coloca este como sendo a alternativa de futuro, contra o agronegócio que é de exploração e destruição da natureza e dos seres humanos. Segundo ela, a Educação do Campo precisa fazer este debate na escola, formando os alunos para a compreensão, mas também para a possibilidade de colocar em prática, tendo a sua unidade de produção (lote de assentamento) como canteiro experimental de uma nova forma de agricultura voltada ao respeito e cuidado com o meio ambiente. "Muitas experiências neste sentido vêm sendo feitas no mundo todo, mas é um trabalho árduo, pois precisa sempre lutar contra a

\footnotetext{
${ }^{3}$ Excerto de fala proferida no Seminário de Educação do Campo, do Curso de Pós-graduação em Educação do Campo do IFC - Campus Abelardo Luz, no dia 14 de março de 2014.
} 
grande força do capital, que trabalha inclusive com a formação e alienação da consciência das pessoas no sentido contrário, do lucro, do individualismo, do ter e do poder" (CALDART, 2014, oral). É nesse sentido que se coloca o papel fundamental da educação e especialmente da educação escolar presente nos espaços de assentamento.

No decorrer do tempo, vários espaços, principalmente relacionados à Reforma Agrária, organizados pelo MST ou por administrações populares, tiveram experiências relacionadas à implementação da Educação do Campo em suas escolas, pautados por metodologias pensadas a partir da pedagogia de Paulo Freire, com Temas Geradores ou Redes Temáticas. Também, mais no âmbito do MST, pela pedagogia socialista Russa, com autores como Pistrak, Shulgin e Vygotsky, tem-se discutido princípios de educação que colocam a realidade como ponto de partida, teoria e prática caminhando juntas, relação da escola com a comunidade, preocupação em formar sujeitos críticos e autônomos, capazes de lutar e construir novas formas de organização da sociedade, mais justas para todos. Ainda, as relações de trabalho, tanto na prática do fazer cotidiano da escola como na teoria, devem discutir e problematizar a exploração dos trabalhadores, a fim de fortalecê-los enquanto classe portadora da tarefa de transformar a sociedade.

Permanecem desafios como: a) a real efetivação das formas pedagógicas da Educação do Campo, com suas demandas de qualidade de educação vinculadas à realidade; b) A construção do conhecimento com teoria e prática, essenciais para a vida das pessoas e formação de sujeitos nas escolas do campo; c) O atendimento universal das populações do campo na educação infantil, ensino fundamental e médio; d) A necessidade de que o ensino superior seja mais próximo do lugar de vida das pessoas, para que não precisem se distanciar dos vínculos da família e da comunidade e possam ainda ajudar a superar dificuldades e transformar, pelo conhecimento adquirido, o lugar onde vivem. Segundo Caldart (2012, p. 263):

No plano da práxis pedagógica, a Educação do Campo projeta futuro quando recupera o vínculo essencial entre formação humana e produção material da existência, quando concebe a intencionalidade educativa na direção de novos padrões de relações sociais, pelos vínculos com novas formas de produção, com o trabalho associado livre, com outros valores e compromissos políticos, com lutas sociais que enfrentam as contradições envolvidas nesses processos. 
Estas considerações remetem a pensar o papel da escola no sentido de fazer acontecer a proposta que reivindicam os povos do campo. Esta proposta deve se contrapor à educação rural existente até então, que não dá conta da função de educar a classe trabalhadora do campo para além do conhecimento básico e desvinculado de seu contexto social.

\section{A formação de educadores, o planejamento por temas e a avaliação descritiva - a experiência da escola}

A Escola Básica Municipal José Maria reelaborou seu Projeto Político Pedagógico (PPP) no ano de 2009 e, de forma participativa, implementou em seu processo pedagógico e organizacional a proposta de Educação do Campo, pensada no âmbito dos movimentos sociais do campo. A partir de 2012, quando inicia o Plano de Desenvolvimento Escolar Interativo (PDI), com recursos do governo federal, a escola passa a organizar uma formação de educadores na própria escola, com o objetivo de pensar um processo diferenciado de planejamento e avaliação que contribuísse para a efetivação do exposto em seus objetivos no PPP. No processo de formação ocorreu a participação da grande maioria dos educadores.

No primeiro momento da formação, coordenada pela equipe pedagógica da escola, juntamente com a professora Dr $^{\mathrm{a}}$. Adriana D’Agostini, educadora da Universidade Federal de Santa Catarina (UFSC), foram retomadas as discussões sobre o PPP, que foi reformulado no sentido de definir objetivos mais diretamente relacionados à Educação do Campo quanto à formação dos educandos e à organização política e pedagógica da escola.

Em um segundo momento, a formação foi direcionada para o estudo de teorias e experiências pedagógicas de educação, realizadas na educação popular e na Educação do Campo, direcionadas a três concepções/metodologias, em especial: Paulo Freire e os temas geradores; Saviani e a pedagogia histórico-crítica; Pistrak, Shulgin e, no Brasil, Luiz Carlos de Freitas, com o Sistema de Complexos, que através de uma produção coletiva, com educadores e pesquisadores do $\mathrm{MST}^{4}$, propõe a pedagogia de complexos para as

\footnotetext{
${ }^{4}$ Coleção Caminhos para a transformação da escola. 1 - Reflexões desde práticas da licenciatura em educação do Campo, 2011. 2 - Agricultura Camponesa, educação politécnica e escolas do campo, 2015. 3 -
} 
escolas do movimento, buscando adaptá-la às necessidades da atualidade. Esta formação tinha o objetivo de orientar os educadores para que pudessem optar por uma proposta metodológica que correspondesse ao objetivo de seu PPP, na perspectiva da construção da Educação do Campo e formação de sujeitos críticos e autônomos.

O quadro a seguir, apresentado pela professora Dr ${ }^{\mathrm{a}}$. Adriana D'Agostini (2013) aos educadores em formação na escola demonstra as abordagens de cada uma das concepções/metodologias estudadas:

Quadro 1 - Concepções/metodologias estudadas na formação dos professores da Escola Básica Municipal José Maria

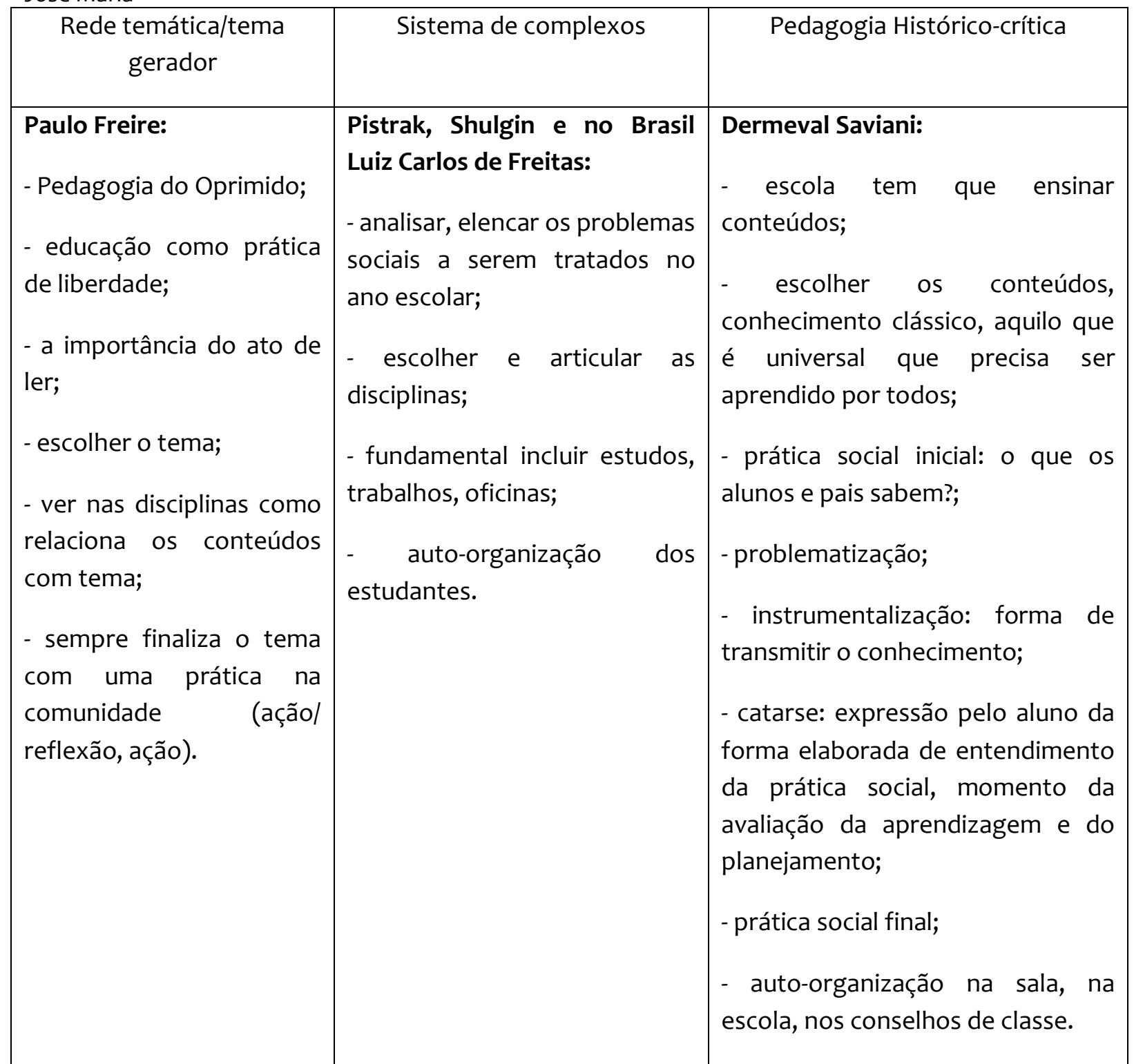

Fonte: (D’AGOSTINI, 2013).

Organização do trabalho pedagógico nas escolas do campo: ensaios sobre complexos de estudo, 2015. Plano de Estudos da escola Itinerante, 2013. 
A partir desta formação, os educadores analisaram as possibilidades e as limitações do que deveria ser o ideal e o que era possível fazer levando-se em consideração o conhecimento e a experiência do grupo. Neste sentido, os educadores, juntamente com a direção e a coordenação pedagógica, optaram, naquele momento, por parte do que seria o ideal a ser feito. Definiu-se, então, pela realização de um planejamento anual e bimestral, por temas, que viriam da realidade dos educandos, relacionados aos conteúdos a serem trabalhados. Assim, não se definiu por um método específico, mas por algo que foi além do tema gerador, a fim de não sucumbir a seus limites historicamente detectados, mas também pelos limites de uma experiência recéminiciada, que não chegaria à complementaridade dos complexos, mas se iniciaria um caminho para tal.

Após um olhar sobre a realidade local, os educadores definiram o tema geral para o ano de 2014: Agricultura Familiar, desmembrado em cinco subtemas relacionados. O planejamento, momento em que se relacionam conteúdos com o tema, foi realizado no início de cada bimestre letivo com a participação de todos os educadores, direção e coordenação pedagógica, com intenção de trabalhar a interdisciplinaridade e a ligação do conteúdo com a realidade. No ano de 2015, o tema e subtemas foram elencados a partir de visitas dos educadores às famílias, com o objetivo de levantar os temas emergentes e necessários à realidade. A metodologia contemplou: visitas às famílias feitas pelos educadores da escola, partilha das falas das famílias visitadas, anotações, sistematização, definição do tema geral e organização dos subtemas. Pela amplitude de temas abordados, estes foram estendidos para o ano letivo de 2016.

A partir do entendimento de que a avaliação interfere de forma ampla na formação do sujeito, que seu resultado por nota não comunica qual é realmente a aprendizagem dos educandos e não representa mais a forma como efetivamente se faz a avaliação na escola, passou-se a discutir a possibilidade de construir outras formas de avaliação. Conforme a determinação da LDB, Lei n. 9394/96, na escola, já há alguns anos, a avaliação qualitativa, prepondera sobre a quantitativa. Por isso, ao final do ano letivo, para aprovar ou reprovar um aluno se avalia o progresso do educando no decorrer do percurso e não o resultado final da soma e divisão de notas. A partir destas constatações, objetivou-se iniciar o processo de implementação do boletim descritivo, por entender que 
este estaria mais coerente com os objetivos de avaliação da escola e ajudaria na comunicação dos aprendizados ou dificuldades dos educandos aos pais.

A partir destas constatações, os educadores da Escola José Maria, em formação pedagógica, decidem pela implantação de uma nova forma de avaliação. Definida no PPP como diagnóstica e processual passa a ser, também, descritiva. Decidem no primeiro momento que se juntaria o parecer descritivo com a nota, até adequar-se o programa de computador de registro da documentação escolar dos educandos. A partir de então, iniciou-se, junto à Secretaria de Educação, o pedido de implantação da proposta.

O instrumento de avaliação, no caso o boletim, foi criado coletivamente pelos educadores, não seguindo nenhum modelo pronto. Este processo iniciou no segundo bimestre de 2014 e foi sendo aprimorado até o primeiro bimestre de 2015, permanecendo o boletim com a descrição e a nota, o que não causou maiores estranhamentos. Ao contrário, houve aprovação da avaliação encaminhada por mais de $80 \%$ dos pais. No segundo bimestre de 2015, com a liberação da Secretaria de Educação, foi possível efetivar no sistema o parecer descritivo. Contudo, parte dos educadores que haviam decidido pela implantação da avaliação descritiva e outros que chegaram à escola depois, apresentaram limites e dificuldades na elaboração do parecer e solicitaram reavaliação da proposta e retorno à nota.

Pelo caminho percorrido na construção coletiva do PPP e as formações na escola, percebeu-se que havia consenso entre os educadores sobre o que se estava construindo. Era perceptível que estavam compreendendo o processo e a maioria participou das decisões, nos limites de tempo e espaço das formações realizadas que foram, em parte, fora do horário de trabalho, sendo que alguns poucos não se dispunham a participar. Naquele momento, ocorreu a decisão política da maioria dos educadores de apoiar e se dedicar à construção da proposta de Educação do Campo na escola. Através da proposta foi possível construir maior unidade entre os educadores e uma identidade positiva para o conjunto da escola frente à educação do município. No entanto, esta decisão política se mostrou bastante frágil, quando houve necessidade de enfrentamento das dificuldades encontradas, prevalecendo interesses pessoais e de poder, o que desmantelou a unidade inicial, fragmentando mais do que antes as relações no ambiente escolar.

De qualquer forma, a experiência e a caminhada do grupo em relação ao 
planejamento coletivo e à avaliação promoveram relações de cooperação e diálogo. Mesmo com a diversidade de opiniões e encaminhamentos, o grupo conseguiu elaborar coletivamente uma linha de ação na escola. O objetivo da avaliação descritiva era favorecer a inclusão e a valorização da diversidade, contrapondo-se ao caráter excludente e classificatório que permeou historicamente a avaliação. Nesse sentido, trataremos a seguir especificamente sobre a avaliação por parecer descritivo e os limites que impediram a consolidação da proposta.

\section{A avaliação por parecer descritivo e os limites da proposta}

A avaliação do rendimento escolar dos estudantes do Ensino Fundamental e Médio, regida pela LDB, Lei n. 9394/96, trata no art. 24, inciso V que:

V - a verificação do rendimento escolar observará os seguintes critérios:

a) avaliação contínua e cumulativa do desempenho do aluno, com prevalência dos aspectos qualitativos sobre os quantitativos e dos resultados ao longo do período sobre os de eventuais provas finais;

b) possibilidade de aceleração de estudos para alunos com atraso escolar;

c) possibilidade de avanço nos cursos e nas séries mediante verificação do aprendizado;

d) aproveitamento de estudos concluídos com êxito;

e) obrigatoriedade de estudos de recuperação, de preferência paralelos ao período letivo, para os casos de baixo rendimento escolar, a serem disciplinados pelas instituições de ensino em seus regimentos. (BRASIL, 1996)

Nesse sentido, a avaliação deve estar voltada à aprendizagem do aluno (sendo a aprovação apenas uma consequência), para a sua inclusão nos processos escolares e na sociedade, como ser ativo, autônomo, ético, informado, participante dos processos de produção e de melhoria social. Conforme Fernandes e Freitas (2007, p. 17):

A avaliação é, portanto, uma atividade que envolve legitimidade técnica e legitimidade política na sua realização. Ou seja, quem avalia, o avaliador, seja ele o professor, o coordenador, o diretor etc., deve realizar a tarefa com a legitimidade técnica que sua formação profissional lhe confere. Entretanto, o professor deve estabelecer e respeitar princípios e critérios refletidos coletivamente, referenciados no projeto político pedagógico, 
na proposta curricular e em suas convicções acerca do papel social que desempenha a educação escolar. Este é o lado da legitimação política do processo de avaliação e que envolve também o coletivo da escola.

De acordo com o PPP, a avaliação tem caráter diagnóstico e processual, pois tem o objetivo de ajudar os educadores a identificarem os aspectos em que os alunos apresentam dificuldades. Nesse processo cabe ao professor refletir sobre sua prática e buscar formas de solucionar problemas de aprendizagem no decorrer do processo e não apenas ao final da unidade ou ao final do ano. Para atender a essa concepção, as etapas a serem desenvolvidas na avaliação da escola são:

Diagnosticar, ou seja, conhecer as condições de aprendizagem, as
dificuldades e possibilidades do aluno; melhorar tais condições e subsidiar
o curso da ação didática a cada etapa do processo, ou seja, corrigir
distorções, indicar possibilidades, modificar estratégias; tomar decisões
referentes à necessária intervenção pedagógica (mudar materiais
didáticos, rever metodologias, apoiar alunos com dificuldades etc).
(ESCOLA BÁSICA MUNICIPAL JOSÉ MARIA, 2014, p. 23)

Assim, a avaliação diagnóstica visa determinar a presença ou a ausência de conhecimentos e habilidades, objetivando saber em qual nível encontra-se o aluno para compreender o processo da produção do conhecimento, a fim de planejar as próximas intervenções, os conteúdos e as estratégias de ensino mais adequadas para que a aprendizagem aconteça. No contexto da escola, avaliação é um dos pontos relevantes para a sua reorganização, ao mesmo tempo em que se observou a necessidade de um maior entendimento por parte dos educadores.

Tradicionalmente, as experiências em avaliação são marcadas por uma concepção que classifica as aprendizagens em certas ou erradas, separa aqueles estudantes que aprenderam os conteúdos programados daqueles que não aprenderam. Essa perspectiva de avaliação classificatória e seletiva é um fator de exclusão escolar (FERNANDES; FREITAS, 2007). Por isso, nas reflexões construídas na escola pelo coletivo de professores, se buscou contrapor à lógica de avaliação que tem o papel de "classificar e excluir" da escola, a seu tempo, os trabalhadores somente com o conhecimento necessário para serem úteis ao mercado de trabalho (FREITAS, 2011, oral). 
Aqui aparece a diferença proposta por Luckesi (1998) entre avaliação e verificação escolar. A avaliação subentende tomada de decisão sobre o aprendizado dos educandos. Se após a avaliação não houver encaminhamentos no sentido de que o educando supere as dificuldades de aprendizagem, não é avaliação e, sim, apenas verificação do estado em que ele se encontra. Luckesi (1998, p. 79) afirma que o conhecimento deve ser o que norteia a ação e avaliação dos educadores na escola e, não, a nota:

Para que se utilize corretamente a avaliação no processo ensinoaprendizagem, no contexto escolar, importa estabelecer um padrão mínimo de conhecimentos, habilidades e hábitos que o educando deverá adquirir; e não uma média mínima de notas, como ocorre hoje na prática escolar.

O autor também afirma que "o ideal seria a inexistência do sistema de notas" e que "a aprovação ou reprovação do educando deveria dar-se pela efetiva aprendizagem dos conhecimentos mínimos necessários, com o consequente desenvolvimento de habilidades, hábitos e convicções" (LUCKESI, 1998, p. 79). Neste sentido, o que importa também para o educando e o que o motivaria a esforçar-se pelos estudos seria o conhecimento necessário ao seu desenvolvimento e não a nota necessária para passar. 0 que moveria a escola seria a "delimitação de conhecimentos mínimos necessários" que ainda, segundo o autor, devem ser definidos de forma coletiva e a partir de conhecimentos científicos constituídos socialmente para não correr o risco de se cair em arbitrariedades (LUCKESI, 1998, p.79).

A experiência de avaliação da escola se desenvolve baseada nos conceitos de Vigotsky (1991), considerando as zonas de desenvolvimento real e proximal do educando, no que é próprio para cada fase da vida. Também, o desenvolvimento de cada um se dá nas relações sociais vivenciadas. Portanto, as diferenças, as potencialidades, os limites, as dificuldades de aprendizagem devem ser entendidos a partir destas relações. Neste sentido, se faz necessário conhecer cada educando e a turma, fase do diagnóstico que precisa ir além do cognitivo, para então planejar as ações e intervenções que, partindo de onde o educando está, o faça progredir. Para Vigotsky (1991), ainda, "é o conhecimento que gera desenvolvimento", por isso a importância de intencionalizar processos de 
ampliação das capacidades de aprendizagem de cada um. Para Gasparin (2011, p. 1975):

Tanto o professor, quanto os alunos possuem uma prática social inicial dos conhecimentos antes que se tornem conteúdos escolares. O fato de por em comum, teoricamente, o conhecimento do professor e a realidade dos alunos oferece elementos para uma avaliação prévia que poderá dar um novo sentido tanto para o ensino quanto para a aprendizagem. Este ponto inicial torna-se um marco para avaliar o crescimento do professor e dos alunos, no decorrer e ao final do processo de ensino e de aprendizagem.

Desta forma, a prática da escola busca uma avaliação processual, que percorre todos os momentos da aprendizagem, no início, no desenvolvimento e ao final. Esta se inicia com o diagnóstico, através do qual o educador observa todo o percurso de desenvolvimento da criança ou adolescente na escola, em todas as atividades realizadas e também com avaliações sistemáticas, e atribui um conceito descritivo da aprendizagem dos conhecimentos trabalhados. Este conceito deve descrever como foi o processo de desenvolvimento, o quanto o educando conseguiu apreender cada conteúdo e quais foram suas dificuldades.

Para tanto, inclusive na avaliação dos instrumentos aplicados pelo professor (provas, trabalhos, seminários, produção de textos, etc.) a nota já não existe e sim um conceito que descreve quais conhecimentos o educando aprendeu e em quais aspectos necessita avançar. Assim, o próprio educando tem a condição de analisar e refletir sobre seu próprio processo de aprendizagem. Ao professor, cabe a intencionalidade no planejamento para a retomada dos conteúdos não aprendidos, visando o que a legislação trata como recuperação paralela. Esta deve ser intencional e organizada pelo educador, para que o educando tenha a possibilidade de aprender o conhecimento não assimilado.

A nota registrada junto ao parecer descritivo, compondo o boletim entregue aos pais no final de cada bimestre, corresponde a um valor atribuído pelo educador a todo o processo de desenvolvimento do educando em relação à vida na sala de aula e nos espaços educativos que lhe foram propostos. Não se refere à soma e média de notas parciais decorrentes de instrumentos diversos de avaliação como provas, trabalhos, relatórios, entre outros. 
Esta forma de conceber a avaliação constituiu-se de uma experiência reflexiva e dialógica bastante interessante no processo escolar, que poderia dar resultados muito positivos num percurso de tempo maior. No entanto, conflitos internos entre os educadores, bem como entre estes e a gestão da escola no sentido da falta de condições objetivas para a aplicação desta sistemática de avaliação, resultaram na negação do processo por parte significativa dos educadores da escola. As questões levantadas pelos educadores, no pedido de retomada da nota, diziam respeito ao limite de tempo despendido para escrever a avaliação que, segundo os mesmos, sacrifica o tempo do planejamento necessário, prejudicando o preparo das aulas. Além disso, argumentaram sobre a necessidade de dedicação de tempo fora do horário de trabalho na escola, o que causa prejuízo às relações familiares. Outra questão colocada foi a da dificuldade de comunicação com os pais, no sentido de não encontrarem palavras adequadas e que fossem de entendimento dos mesmos quanto ao resultado da aprendizagem de seus filhos.

Contudo, em nenhum momento os educadores negaram a importância do parecer descritivo, afirmando reconhecer sua relevância na avaliação dos educandos. No entanto, entenderam não ser possível realizá-la neste formato de escola e no tempo de um terço de hora atividade que se dispõe para o planejamento e as atividades de avaliação. A avaliação diagnóstica e processual permaneceu como concepção; contudo, foi retomado o processo de classificação do conhecimento do educando através de notas e médias. Isso não necessariamente modificou a prática de todos os professores em relação ao processo realizado anteriormente, mas retirou a proposta enquanto adesão coletiva, o que muda toda a lógica da concepção da avaliação descritiva discutida na escola.

O planejamento coletivo por temas relacionados à realidade dos educandos continuou sendo aplicado por maior período. Atualmente, após a mudança de administração no início do ano de 2017, todo este processo, tanto de avaliação descritiva, que já havia sido interrompido em meados do segundo semestre de 2015 e o planejamento por temas, que com limitações ainda continuou sendo aplicado até final de 2016, foi totalmente interrompido. A orientação da direção da escola é de que cada educador, individualmente, siga em seu planejamento os conteúdos listados e a metodologia da proposta curricular de educação da rede municipal, sem nenhum 
planejamento coletivo entre os educadores da escola. Ou seja, não há nenhum esforço para a continuidade e fortalecimento da proposta de Educação do Campo, de acordo com seu contexto e necessidades e, muito menos, que leve em consideração os princípios orientadores da educação do MST, com exceções pontuais de educadores que buscam pautar sua prática pedagógica nesta concepção.

\section{Considerações finais}

A partir do percurso exposto, percebemos a importância da formação de educadores na escola, pois possibilita a ampliação do conhecimento e a participação dos mesmos na construção coletiva do projeto pedagógico. Este processo tornou mais consciente o percurso da escola na construção de seus objetivos e permitiu discutir os temas planejamento coletivo e avaliação sob diferentes nuances, além de atentar para os aspectos legais relacionados à avaliação, bem como discutir o tema em sintonia com as formas de construção de espaços conquistados pelo MST e pela concepção pedagógica da Educação do Campo, fenômeno recente da educação brasileira. Assim, frente à experiência aqui descrita e discutida, podemos destacar três questões principais que nortearam a prática pedagógica da escola: o planejamento coletivo; o planejamento por temas; e a avaliação, com seus avanços, limites e desafios.

O planejamento coletivo é um processo que dá unidade à escola e, na partilha de conhecimentos, amplia o aprendizado de todos, além de possibilitar a colaboração e troca entre os educadores com mais e menos experiência. O limite e desafio para o planejamento se dão no engessamento da forma escolar e na falta de tempo, assim como ocorreu na tentativa de instituir a avaliação descritiva. Por isso, estes processos permanecem em construção na escola e são essenciais para a objetivação da proposta no PPP. As discussões em torno das concepções de Educação do Campo e dos princípios de educação do MST foram fundamentais para o coletivo de educadores definirem a proposta de planejamento das aulas.

O Planejamento por temas possibilitou relacionar, problematizar e compreender melhor as questões da realidade, tendo como ponto de partida problemas ou temas identificados a partir da visão das famílias. Conforme o $3^{\circ}$ princípio pedagógico do MST, a 
realidade é a base da produção do conhecimento. Isso significa não apenas "partir da realidade", mas ter a realidade como ponto de chegada para o conhecimento que queremos produzir. Ou seja:

A produção do conhecimento é uma das dimensões do processo educativo. Então, através deste princípio estamos dizendo que precisamos nos preocupar em como garantir que nossos educandos/nossas educandas produzam conhecimento. Conhecimento sobre o quê? Sobre a realidade. Mas quando falamos em realidade não estamos nos referindo apenas à realidade que nos cerca, a que vivemos ou enxergamos. A realidade é o mundo! É tudo aquilo que existe e que merece ser conhecido, apreciado, transformado e que pode estar a milhares e milhares de quilômetros do nosso assentamento. Só que não tem sentido conhecermos todo o mundo sem conhecermos o nosso assentamento. (MST, 2005, p. 167)

Nesse sentido, conhecer a realidade é condição para transformá-la. Aqui se percebem avanços na proposta construída, sendo o maior limite e desafio, ao mesmo tempo, a integração dos temas da realidade com os conteúdos a serem trabalhados, que representam o conhecimento científico historicamente construído.

A avaliação, diagnóstica e processual com parecer descritivo, merece destaque no sentido de afirmar sua importância em relação ao fato de possibilitar planejar a ação da escola, delimitando verdadeiramente os conhecimentos necessários para o desenvolvimento da vida, propostos pelas concepções aqui citadas, e não baseada na preocupação de atingir uma nota para passar de ano. Faz toda a diferença pensar na escola a progressão de seus educandos a partir dos conhecimentos essenciais para a formação dos mesmos, em vez de realizar médias gerais dos conhecimentos ensinados, muitas vezes sem reflexão de sua importância. No entanto, é justamente neste ponto, que mexe mais profundamente na estrutura da escola, que se encontraram as maiores dificuldades e resistências.

Como limites em relação à proposta de avaliação descritiva, identificamos a falta de conhecimento, por parte dos educadores, da própria Pedagogia da Educação do Campo, apontando que os estudos realizados na escola não foram suficientes para superar tal dificuldade. Os limites de ordem financeira, organizacional e de tempo dentro 
do período do ano letivo, no sentido de ampliar tais conhecimentos, influenciaram sobremaneira. Há, ainda, a necessidade para a construção de tais processos, de uma ampla dedicação por parte dos educadores, bem além do usual.

A avaliação dos limites apontados pelos educadores, principalmente no que diz respeito ao tempo, um dos maiores entraves apontado por eles, remete para o engessamento da forma de organização dos sistemas escolares, que não dão conta de integrar processos inovadores, o que demanda uma profunda reflexão para a transformação da forma escolar. Para o MST, que historicamente vem construindo sua proposta de educação, este é um desafio permanente que continua sendo estudado e experimentado nos limites das contradições de um sistema de sociedade hegemônico que não concorda com os mesmos princípios. Por isso, apontamos aqui a necessidade de pesquisa relacionada ao estudo da forma escolar, e à projeção de uma escola que possa se adequar à proposta.

Os educadores da escola, ao optarem por voltar à nota, mas ao continuarem o planejamento por temas, de forma coletiva, demonstraram, ao menos inicialmente e em parte, assumir a tarefa da construção de uma educação voltada para a classe trabalhadora do campo; não de qualquer educação, mas através da proposta da Educação do Campo, pensada pelos movimentos sociais do campo. No entanto, assim como já aconteceu nas mesmas escolas em épocas anteriores, as mudanças políticas administrativas têm o poder de interromper processos, o que demonstra a fragilidade organizacional dos sujeitos da escola que defendem e buscam colocar em prática propostas de educação mais populares. Os educadores não se empoderaram do conhecimento necessário para compreender a proposta, o que dificulta levá-la adiante ou lutar por ela.

Toda esta caminhada, entre avanços e retrocessos, demonstra as contradições da sociedade capitalista, da qual a escola é parte, determinada por esta, mas, por outro lado, é um espaço fecundo para questionar e propor um caminho que se oponha à visão hegemônica imposta pelo capital. Para alcançar tais objetivos, se faz necessário o conhecimento da realidade que engloba a vida dos povos do campo, a construção de um projeto de educação voltado à transformação da realidade e da própria escola.

A escola tem o desafio da continuidade da formação dos educadores, interna e 
externamente, junto com as demais escolas do campo, principalmente em área de assentamento, olhando para o projeto de educação que vem sendo construído pelo MST, o que pode contribuir muito, já que é com organização e reflexão coletiva que a escola se constrói. Outro desafio é a organização do tempo para estudo, planejamento, reflexões e, acima de tudo, o empenho de cada educador em um processo coletivo, para que se estabeleçam os objetivos e caminhos necessários à efetivação do projeto de escola proposto.

O $11^{\circ}$ princípio pedagógico do MST, que trata da criação de coletivos pedagógicos e formação permanente dos educadores/ das educadoras, assim se refere ao papel da coletividade no processo educativo e que nos aponta um dos grandes desafios da escola para a construção da educação do campo com base em práticas emancipadoras:

Sem uma coletividade de educadores não há verdadeiro processo educativo. 'Nenhum educador tem o direito de atuar individualmente, por sua conta e sob sua responsabilidade'. (Makarenko). Parece uma afirmação muito forte? Mas ela é uma lição também da nossa prática. Um professor ou uma professora que trabalhe só, não consegue pôr em ação estes princípios pedagógicos que aqui estamos defendendo. Eles nasceram de um esforço coletivo e é pela cooperação que se realizam. (MST, 2005, p. 174) 


\section{Referências}

BRASIL. Constituição da República Federativa do Brasil de 1988. Disponível em: <http://www.planalto.gov.br/ccivil_03/constituicao/constituicaocompilado.htm>. Acesso em: 16 jul. 2015.

BRASIL. Lei $\mathbf{n}^{\circ}$ 9.394, de 20 de dezembro de 1996. Estabelece as diretrizes e bases da educação nacional. Disponível em:

<http://www.planalto.gov.br/ccivil_03/leis/L9394.htm>. Acesso em: 17 jul. 2015.

CALDART, Roseli Salete. Educação do Campo. In: CALDART, Roseli; PEREIRA, Izabel, Brasil; FRIGOTTO, Paulo Alentejano (Orgs.). Dicionário da educação do campo. Rio de Janeiro: Escola Politécnica de Saúde Joaquim Venâncio; São Paulo: Expressão Popular, 2012.

CALDART, Roseli Salete. In: SEMINÁRIO DE EDUCAÇÃO DO CAMPO, CURSO DE PÓSGRADUAÇÃO - IFC, Abelardo Luz, 2014. Palestra. 2014

CHEROBIN, Fabiane Fátima. A educação do campo e sua normatização como política pública: uma demanda dos trabalhadores ressignificada pelo Estado. 2015. Dissertação (Mestrado) - Universidade Federal de Santa Catarina. Centro de Ciências em Educação. Programa de Pós-Graduação em Educação. Florianópolis, 2015.

D`AGOSTINI, Adriana. Formação de educadores na Escola Básica Municipal José Maria, 26 out. 2013. Oral e exposição em quadro negro e slides.

ESCOLA BÁSICA MUNICIPAL JOSÉ MARIA. PPP - Projeto Político Pedagógico. Abelardo Luz, 2014.

FERNANDES, Bernardo Mançano; WELCH, Clifford Andrew; GONÇALVES, Elienai Constantino. Os usos da terra no Brasil: debates sobre políticas fundiárias. São Paulo: Cultura Acadêmica/Unesco, 2014. (Vozes do Campo)

FERNANDES, Cláudia de Oliveira; FREITAS Luiz Carlos de. Indagaçõos sobre currículo: currículo e avaliação. Brasília: Ministério da Educação; Secretaria de Educação Básica, 2007.

FREITAS, Luiz Carlos de. A Escola única do Trabalho: explorando os caminhos de sua construção. In: CALDART, Roseli Salete (Org.). Caminhos para a transformação da escola: desde práticas de licenciatura em educação do campo. São Paulo: Expressão Popular, 2011.

GASPARIN, João Luiz. Avaliação na Perspectiva Histórico-Crítica. In: CONGRESSO NACIONAL DE EDUCAÇÃO. EDUCARE, 10, 2011, Curitiba. Anais... Curitiba: PUC Paraná, 2011.

IBGE. Abelardo Luz: população. Rio de Janeiro: IBGE. Disponível em: <https://cidades.ibge.gov.br/v4/brasil/sc/abelardo-luz/panorama>. Acesso em: 16 jun. 2017. 
KOLLING, Edgar Jorge; CERIOLI, Paulo Ricardo; CALDART, Roseli Salete (Orgs.). Educação do campo: identidade e políticas públicas. Brasília, DF: Articulação Nacional por uma Educação do Campo, 2002. Coleção Por Uma Educação do Campo, n. 4.

LUCKESI, Cipriano Carlos. Verificação ou avaliação: o que pratica a escola? São Paulo: FDE, 1998. (Série Ideias, n. 8)

MOVIMENTO DOS TRABALHADORES RURAIS SEM TERRA (MST). Dossiê MST escola.

Documentos e estudos 1990-2001. Edição Especial, Ago. 2005.

OLIVEIRA, Mary Carneiro Paiva. Educação do campo: concepção, contribuições e contradições. Revista Espaço Acadêmico. Maringá (PR): UEM, n. 140, p. 43-52, jan. 2013. Disponível em:

<http://periodicos.uem.br/ojs/index.php/EspacoAcademico/article/view/18301>. Acesso em: 12 nov. 2015.

PIRES, Marília Freitas de Campos. O materialismo histórico dialético e a educação. 1997. Disponível em: <http://www.scielo.br/pdf/icse/v1n1/06.pdf>. Acesso em: 18 out. 2014.

RIBEIRO, Marlene. Educação Rural. In: CALDART, Roseli; PEREIRA, Izabel, Brasil; FRIGOTTO, Paulo Alentejano (Orgs.). Dicionário da educação do campo. Rio de Janeiro: Escola Politécnica de Saúde Joaquim Venâncio; São Paulo: Expressão Popular, 2012.

VIGOTSKY, Lev Semenovich. A Formação social da mente: o desenvolvimento dos processos psicológicos superiores. 4. ed. São Paulo: Martins Fontes, 1991.

Universidade do Estado de Santa Catarina - UDESC Programa de Pós-Graduação em Educação - PPGE

Revista Linhas

Volume 19 - Número 39- Ano 2018 revistalinhas@gmail.com 